\title{
How to choose and become a reviewer for a scientific medical journal
}

\author{
Paola Gnerre, ${ }^{1}$ Giorgio Vescovo, ${ }^{2}$ Paola Granata, ${ }^{3}$ Cecilia Politi, ${ }^{4}$ Andrea Fontanella, ${ }^{5}$ Dario Manfellotto, ${ }^{6}$ \\ Roberto Nardi ${ }^{7}$
}

${ }^{1}$ Internal Medicine, San Paolo Hospital, Savona; ${ }^{2}$ Internal Medicine, A.U.L.S.S. 6, Padova; ${ }^{3}$ PAGEPress Scientific Publications, Pavia; ${ }^{4}$ Internal Medicine, F. Veneziale Hospital, Isernia; ${ }^{5}$ Internal Medicine, Buonconsiglio Hospital, Napoli; ${ }^{6}$ Internal Medicine, Fatebenefratelli Hospital, Isola Tiberina, Roma; ${ }^{7}$ Internal Medicine, Bologna, Italy

\begin{abstract}
Peer review is the process of subjecting an author's scholarly work, research or ideas to the scrutiny of others who are experts in the same field. The peer review of scientific manuscripts is a cornerstone of modern science and medicine. Some journals have difficulty in finding appropriate reviewers who are able to complete reviews on time avoiding publication delay. We discuss some of the main issues involved during the peer review process. The reviewer has a direct and important impact on the quality of a scientific medical Journal. Editors select reviewers on the basis of their expertise. Reviewers are more likely to accept to review a manuscript when it is relevant to their area of interest. They should respond to ethical principles, excluding any conflict of interest condition. The reviewer has to be professional, constructive, tactful, empathetic and respectful. Structured approaches, quality indicators and step-by-step process check list formats could be useful in obtaining a good review.
\end{abstract}

The Reviewer is a consultant: his goal is to improve the paper at hand, not to make it into a different study

\section{Introduction}

Peer review is the process of subjecting an author's scholarly work, research or ideas to the scrutiny of others who are experts in the same field. The Institute for Scientific Information only considers journals that are peer-reviewed as candidates to receive Impact Factors. ${ }^{1}$ In Internal Medicine the job of a reviewer is multifaceted, including several skills, referred not only to the expertise in the specific field required, but also to his competencies in evidence-and value-based medicine, statistics, ethics and clinical judgment in the

Correspondence: Roberto Nardi, Internal Medicine, Bologna, Italy.

E-mail: nardidoc48@gmail.com

Key words: Peer review; publishing process; quality of a journal.

Received for publication: 11 March 2018.

Revision received: 12 May 2018.

Accepted for publication: 17 May 2018.

This work is licensed under a Creative Commons Attribution NonCommercial 4.0 License (CC BY-NC 4.0).

CCopyright P. Gnerre et al., 2018

Licensee PAGEPress, Italy

Italian Journal of Medicine 2018; 12:151-158

doi:10.4081/itjm.2018.1016 complexity of real word. ${ }^{2}$ Reviews have a direct and important impact on the quality of a journal. The emphasis of our reviews should be to help the authors on how to improve their work and therefore to improve the overall quality of the work in our research community. In this technical note we will use interchangeably the terms of a reviewer (as a person who writes critical reviews for a newspaper or other publication) and a referee (as an expert who judges the manuscript of an article or book to decide if it should be published).

\section{Who gets invited to review? Between difficulties and opportunities}

Someone believes that there is little evidence that the peer review process actually works effectively. ${ }^{3}$ For this reason we must be sure to involve talented professionals who can ensure an adequate editorial process to our expectations. In general, editors need to invite 6 to 7 reviewers to get 2 to 3 acceptances to review, but for about one out of eight papers, editors have to invite 10 or more referees to get enough acceptances. ${ }^{4}$ On average, a reviewer will conduct approximately eight reviews per year, according to a study on peer review by the Publishing Research Consortium (PRC). ${ }^{5}$ Time needed to review one paper is around six hours. ${ }^{6}$ Peer reviewer can be anyone who has competence and expertise in the subject areas that 
the journal covers. Reviewers are more likely to accept to review a manuscript when it is relevant to their area of interest. Lack of time is the principal factor in the decision to decline. ${ }^{7}$ Some general criteria may be useful in choosing reviewers: i) recognized experts in the field, including women; ${ }^{8}$ ii) do not only recommend the biggest names in the field: the probability that they can comply with your request is minimal; iii) do not look for reviewers among your friends. The main goal of peer review is to assess and improve manuscripts before publication. Choosing some friends that will not challenge your research in any way will deprive the objective possibility to improve your manuscript; iv) junior reviewers (generally the most responsive), under the supervision of a mentor if necessary; $v$ ) expert and updated retired professionals, with a lot of free time available; vi) editorial board members (providing about $30 \%$ of reviews); vii) potential reviewers recommended by the authors, better if not personally known to them.

We have to assure the anonymity of the reviewing process. Journals will keep a rather large reviewer bank, so that reviewers do not get burnt out, overwhelmed or time constrained from reviewing multiple articles simultaneously. Reviewers are asked to decline if: i) there is a real or perceived conflict of interest (see further); ii) they cannot review in a timely manner (at most 2 weeks); iii) the content is out of their area of expertise. ${ }^{9}$

\section{Ethical responsibilities of a reviewer (but for Editors too)}

Adherence to ethics requires a more careful analysis of the paper as well as a more time spending in our review, counterbalanced by the opportunity of getting a better result for both the manuscript and the journal. ${ }^{10}$ The idea is that everyone should get a similar and unbiased review. First, the reviewer has to operate according to a specific peer review policy applied by the Journal (e.g., single- vs double-blind peer review are the most common methods; for a deep discussion, see the next paragraph). The reviewer has to provide an honest, critical assessment of the research, accepting manuscripts for review only in his/her areas of expertise. ${ }^{11}$ She/he has the unpleasant responsibility of reporting suspected duplicate publication, fraud, plagiarism, or other ethical concerns in the research. Plagiarism is a common problem. ${ }^{12}$ It occurs whenever you use either without proper attribution: 'if you paraphrase another author's ideas in your own words then you need a citation, but, if you copy verbatim another author's words then you need to put the copied text in quotes and include a citation ${ }^{13}$ Peer reviews are often criticized for being unable to accurately detect plagiarism. Obviously, the responsibility lies with the author and not the reviewers. In this task, Editors, webmasters and copyright holders could help reviewers in detecting plagiarism by implementing electronic tools, such as Similarity Check, ${ }^{14}$ the Déjà $v u$ database, ${ }^{15}$ iThenticate, ${ }^{16}$ Plagiarism Today. ${ }^{17}$ In turn, the reviewers must not fall into plagiarism by getting out ideas, data and novel concepts from a paper before the manuscript is published. Their task is to protect ideas not to appropriate them. Our Italian Journal of Medicine (ITJM) refers to the Recommendations on Publication Ethics Policies for Medical Journals, prepared by the Word Association of Medical Editors (WAME) Publication Ethics Committee (Table 1). ${ }^{18,19}$

\section{Single- or double-blind peer review? A third way of review exists}

Even if single-blind peer review is the traditional mode most commonly used in the peer review process, double-blind peer review has been introduced with the aim to reduce/avoid bias. However, many issues still need to be discussed about the pros and cons in using one or the other mode in the review process, and a third one has been recently hypothesized as the possible solution: the open peer review.

First of all, single-blind peer review is intended when authors do not know the referees' names, but on

Table 1. The peer review process in the Italian Journal of Medicine.

\footnotetext{
All of our journals follow the WAME Recommendations on Publication Ethics Policies for Medical Journals ${ }^{18,19}$ about peer review. The Editorial Board of each journal will immediately screen all articles submitted for publication in that journal. Those articles, which fail to reach the scientific standards of the journal, may be declined without further review. Those articles, which satisfy the requirements of the Editorial Board, will be sent to a maximum of three referees. These are experts in the field who have agreed to provide a rapid assessment of the article. Every effort will be made to provide an editorial decision as to acceptance for publication within 4-6 weeks from submission. Referees may request a revision of the article to be made. In this case, it is generally understood that only one revised version can be considered for a further appraisal under the peer review system. The Editorial Board of each journal is responsible for the final selection of referees to conduct the peer review process for that journal. The names of referees will not be made available to authors. However, referees will be informed as to the identity of the authors whose articles are subject to review. All members of the Editorial Board and referees are asked to declare any competing interests they may have in reviewing a manuscript. If on receiving the editorial decision concerning their manuscript authors are not satisfied they are invited to appeal to the Editorial Office. In cases in which this is considered appropriate a second opinion on the manuscript will be requested.
} 
the contrary the referees may access to authors' names and affiliations. Double-blind peer review is intended when any information about both authors and referees is hidden and unknown to both parties.

There is a long-standing debate about whether it is more reasonable to anonymize a submission or not: i) supporters of the single-blind method advocate that to guarantee a complete anonymity may be difficult, if not impossible (also considering the increasingly common practice of publishing preprints); it causes problems in the detection of any possible conflicts of interest, or in evaluating a work because it is more complex to contextualize the research direction; a biased assumption that authors hiding their identities produce lower-quality work is widespread. Also, a waste of time is frequent because referees try to identify the authors' identities, and this may affect their final judgment in the case they guess correctly or not: ${ }^{20,21}$ ii) on the other hand, supporters of the double-blind method endorse the idea that knowledge of the authors introduces undesirable - conscious or unconscious - biases in the reviewing process (such as, prejudice against authors from a certain country, race, or gender; more recognition to papers from already-famous researchers, or the fame or quality of the institution where the study was carried out). ${ }^{20}$ But the objectivity of the double-blind peer review may provide a false sense of security (e.g., well-known authors can be easily identified by the structure of their work, even if their names are blind), affecting the detection of any possible conflict of interest. ${ }^{22}$

Bias in peer review is a real problem ${ }^{22}$ and it mainly affects women, ethnic minorities, and researchers from non-prestigious institutions. ${ }^{22}$

As the double-blind peer review may not actually eliminate bias, some researchers have advocated for a third modality of reviewing: the open peer review, in which both authors' and reviewers' identities are known. $^{21,22}$

This possible solution, which is becoming the subject of many debates, requires a much greater assumption of responsibility, given that the people involved have to put their faces and their names to it.

\section{Conflict of interest}

Declarations about conflict of interest (COI) should be explicitly requested for reviewing a manuscript. COI relates to a state, not to our behaviors: it exists whenever there is a divergence between an individual's private interests (competing interests) and his or her responsibilities to scientific and publishing activities. ${ }^{23} \mathrm{COI}$ includes cases when a potential reviewer has published or worked with the author recently or is sponsored by a pharmaceutical company related to the work under review. Financial ties occur when a participant in the publication process has received or expects to receive money (or other financial benefits such as patents or stocks), gifts, or services that may influence work related to a specific publication. Personal relationships with family, friends, enemies, competitors, or colleagues can pose COI. Political or religious beliefs could be considered in COI. Several other conditions define a state of COI: i) if you acknowledge that you have a friendly relationship with one of the authors; ii) you are a coauthor in the reviewing work; iii) you have a prior or current collaboration with the author(s); iv) you may have a known history of antipathy with the author(s); v) you have a strong affiliation with the same institution of authors; vi) you are family related to one of the co-authors. Any conflicts of interest must be avoided while conducting peer review. If referees have a COI with the content or authors of a manuscript, they should be excluded from the review process.

\section{How to be an effective peer reviewer}

Reviews will be expected to be professional, honest, courteous, prompt, and constructive. Should the referees be overcommitted and have to decline the request, she/he should be so kind to inform the Editors about their need to be replaced, in timely manner avoiding any delays. In that case, a suggestion for other suitable and reliable reviewers with sufficient experience in the field related to the paper is much appreciated. The manuscript should not be retained or copied; also, reviewers must not share it with any colleagues without the explicit permission of the editor. ${ }^{24}$

The following tips synthetically report how to be an effective peer reviewer (Table 2). ${ }^{25-30}$

\section{Admission criteria for publication in the Italian Journal of Medicine}

The ITJM main focus and scope are: i) describing the complex and variable situations confronted by Internists in daily practice; ii) promoting excellence in the practice of internal medicine in hospitals and disseminating the results of clinical research; iii) updating of hospital internists on general topics concerning public health, including ethical, legal, economical and health policy issues. ${ }^{31}$

When reviewing a paper for ITJM, a referee must be aware about the above-mentioned focus and scope admission criteria, in order to help the Editor-in-Chief and the Associate Editors in making a first selection of papers worthy to undergo peer review phase.

Once the article appropriateness for the journal readership is established and the manuscript priority 
ranking relative to other manuscripts under consideration is defined (since the number of papers that the journal receives is much greater than it can publish), the peer review phase can start.

Prior to start reading the assigned paper, the selected referee(s) is/are warmly invited to check and revise the Guidelines and Editorial standards available from the journal website ${ }^{32}$ and keep them in mind during the whole revision process.

In particular, at a first glance evaluation, she/he should detect the following points related to the ethical standards: i) the submission has not been previously published (plagiarism); ii) in case of clinical trials, a note about their registration in a public accessible trials registry must be clearly stated; iii) a documented review and approval from the Institutional Review Board or Ethics Committee is required for all studies (prospective or retrospective) involving people, medical records, and human tissues.

If reviewers suspect any misconduct, they should report it to the Editor in confidence, and should not share their concerns with other parties unless officially notified by the Journal. ${ }^{24}$

At the same time, she/he should detect also the following points related to the editorial standards: ${ }^{32}$ i) the document file format and the text adhere to the stylistic and formatting requirements outlined in the Author Guidelines; ii) the reviewer should verify the bibliographic references (whether data are accurate, complete, easy to find, etc., or not), and ensure that all citations are relevant and pertinent to the paper topic. If not, she/he should instruct the authors in order to reduce/correct them; in particular, attention should be paid to self-citations only added in order to increase

Table 2. Tips to be an effective peer reviewer.

\begin{tabular}{|c|c|c|}
\hline 1 & Be timely and respectful of the commitments & $\begin{array}{l}\text { It is important to be timely both for respect to the journal and the author, but also not to } \\
\text { delay the publishing process. If unexpected reasons for delay arise the reviewer } \\
\text { should immediately contact the editor }\end{array}$ \\
\hline 2 & $\begin{array}{l}\text { Be professional and make your review as } \\
\text { objective and evidence-based as possible }\end{array}$ & $\begin{array}{l}\text { Peer review is a mutual responsibility among fellow scientists. We must share professional } \\
\text { values. Search the literature for systematic reviews on the same topic. Using keywords } \\
\text { and the title of the article }{ }^{25} \\
\text { The CONSORT statement is a useful tool for reviewing randomized trials }{ }^{26} \\
\text { Cohort, case-control, and cross-sectional studies should conform to the format suggested } \\
\text { by the STROBE panel }{ }^{27} \\
\text { Reporting of meta-analyses should conform to the PRISMA Statement criteria }{ }^{28}\end{array}$ \\
\hline 3 & Be constructive, tactful and pleasant & $\begin{array}{l}\text { Review should be written in a collegial, constructive manner. Sarcastic comments are } \\
\text { unnecessary. Avoid aggressive and scathing reviews, which can ward off potential authors } \\
\text { to submit papers to our journal. Your criticism should be able to sustain a productive } \\
\text { discussion with authors. Have an open mind, think about your potential biases and try to } \\
\text { eliminate them in the review }\end{array}$ \\
\hline 4 & Be empathetic and respectful & $\begin{array}{l}\text { Ensure that the review is scientific, helpful and courteous. Be sensitive and respectful with } \\
\text { word choice and tone in a review } \\
\text { Be careful not to review the other reviewers' comments. Do not argue with the other } \\
\text { reviewers in your comments to the authors }\end{array}$ \\
\hline 5 & Be helpful and open & $\begin{array}{l}\text { Suggest how the authors can overcome the shortcomings in their paper. A review should } \\
\text { guide the author on what is good and what needs work from the reviewer's perspective. } \\
\text { Recognize that both specialists and generalists can provide valuable information during } \\
\text { peer review }\end{array}$ \\
\hline 6 & Be scientific and rigorous in finding errors & $\begin{array}{l}\text { When performing a peer review, there are some common scientific errors to look out for, } \\
\text { such as: } \\
\text { - poor legibility and clarity of the text } \\
\text { - violations of logic and common sense: contradicting statements, unwarranted } \\
\text { conclusions, suggestion of causation when there is only support for correlation, } \\
\text { inappropriate extrapolation, circular reasoning, or pursuit of a trivial question } \\
\text { - bias (in the planning, selection of cases, data collection, statistical, analysis, and } \\
\text { publication phases of research) } \\
\text { - failure to define terms or use words with precision, as these practices can mislead readers } \\
\text { Identify, according to your experience and gut feeling, any specific problem to each paper }\end{array}$ \\
\hline 7 & Be scientific and systematic & $\begin{array}{l}\text { Focus on adding value with scientific knowledge and commenting on the credibility of } \\
\text { the research conducted and conclusions drawn } \\
\text { Comment according to a pre-ordered check list of actions/criteria required }\end{array}$ \\
\hline 8 & Be organized & A review requires structure and logical flow \\
\hline 9 & Be realistic & $\begin{array}{l}\text { The peer reviewer must be realistic about the work presented, avoiding asking for paper } \\
\text { changes that are too ambitious and not congruent with the initial objectives of the work }\end{array}$ \\
\hline & Stay on the matter & $\begin{array}{l}\text { You should never propose to do another study, but try to pursue in your judgment the } \\
\text { author's goals } \\
\text { Ask the authors to resume the key messages of their study }\end{array}$ \\
\hline
\end{tabular}

Sources: ${ }^{29,30}$ 
personal impact factor or the visibility of a friends' journal; iii) check and evaluate the readability of Figures and Tables, both for scientific content and graphic presentation; iv) if material which has already been published is used, a copy of the written permission for the reproduction and adaptation has to be provided before publication, and appropriately cited in each caption. The procedure for requesting the permission is the responsibility of the authors; referees should remind authors about that: alternatively, they should advise to use materials from other (free) sources.

All the above-listed points are admission criteria that have to be considered prior to start the in-deep scientific evaluation and decide whether proceeding with the peer review phase or not; otherwise, submissions not adhering to those criteria must be returned to authors.

\section{Approaching a paper and writing the review}

Your review should be written in a direct, constructive and scholarly way. Sentences should be phrased in such a way as not to degrade or belittle the authors. Specific issues concerning interpretation of data or discussion points should include pertinent references when necessary. You are not obliged to reanalyze or re-draw the data but you can make suggestions that the authors do so. Finally, remember that your review needs to be written as well as you would want the manuscript to be written. When a manuscript is revised, the authors should respond to the concerns of each reviewer on a point-to-point basis.

\section{Primary questions to ask}

Our initial check should evaluate the overall structure of the manuscript in its components (Title, Introduction, Materials and Methods - including Statistical analysis - Results, Discussion, Conclusions and References). Those parts must be complete and coherent. ${ }^{33}$ Regarding the contents, we have firstly to ask some basic questions: ${ }^{9}$ i) Is the research question important and original? This process may be supported by a literature search; ii) Is the scientific approach appropriate for answering this question? iii) Are there obvious omissions? iv) Are conclusions supported by data? v) Is the statistical method appropriate?

\section{Initial evaluation: a tactical approach}

As a first approach, carefully read the cover letter, accompanying the Author's submission. You can use the abstract, figures and tables to understand the sense of the overall goals and methodology of the study. Read conclusions at the end of discussion and, if available, the key messages that the authors want to offer with their paper to the medical literature as novelty and/or added value.

\section{Proceed for a more in-depth evaluation}

Read the entire paper, paying attention to the details. Ask yourself if the basic question has been addressed by the protocol and methods used. Similarly, data quality and interpretation can support the conclusion. Exclude the possibility of type II (false negative) errors from underpowered studies.

\section{Abstract evaluation}

The abstract alone is often used to assess the value of a manuscript. ${ }^{34}$

\section{In the review a checklist format can be useful}

Some checklist for reviews include issues for comment, such as: i) importance of research question; ii) originality of work; iii) highlighting of strengths and weaknesses of methodology/experimental/statistical approach/interpretation of results; iv) writing style (including redundancies and repetitions) and figure/table presentation; v) ethical concerns. The following checklist may be useful for guiding the reviewer step by step in his referrals (Table 3 ). ${ }^{35}$

\section{Proceed according to a structured approach and quality indicators}

A useful suggestion can be to follow the indications of the IMRaD model (Table 4). ${ }^{36,37}$

Good and bad reviews depend on some elements shown in Table 5. ${ }^{9}$

\section{Reviewing a revised manuscript}

At this point you have to understand if the authors were responsive to your suggestions and if the revision is scientifically acceptable. The authors should explain why your concerns were not acted and carry out additional analyses or experiments if requested as recommended. If they did not, they should justify why this.

\section{Conclusions}

Peer review is fundamental in assisting editors in selecting credible, high quality, novel and interesting research papers to publish in scientific journals. Some journals have difficulty in finding appropriate reviewers who are able to complete timely reviews, thus resulting in publication delay. How to implement acknowledgement or incentive to facilitate and speed 
Table 3. An example of a step-by-step reviewing process checklist of a paper. ${ }^{35}$

\begin{tabular}{|c|c|c|c|c|c|c|}
\hline \multicolumn{7}{|l|}{ General criteria } \\
\hline Issues & & $\begin{array}{c}1 \\
\text { Minimal }\end{array}$ & 2 & 3 & 4 & $\begin{array}{c}\mathbf{5} \\
\text { Superior }\end{array}$ \\
\hline \multicolumn{7}{|c|}{$\begin{array}{l}\text { Importance/interest of research question } \\
\text { Appropriateness for our Journal } \\
\text { Originality of work/idea } \\
\text { Study design validity and appropriateness } \\
\text { Organization of the text and paragraphs } \\
\text { Writing style and grammar } \\
\text { Written English language } \\
\text { Adequacy of figures and tables } \\
\text { Relevance of the discussion } \\
\text { Conclusions and interpretation } \\
\text { References-format citations }\end{array}$} \\
\hline \multicolumn{7}{|l|}{ Quality } \\
\hline $\begin{array}{l}\text { Superior } \\
\text { Good } \\
\text { Fair } \\
\text { Poor }\end{array}$ & & Explain: & & & & \\
\hline \multicolumn{7}{|c|}{ Strengths and weaknesses in the paper } \\
\hline Methodology of the study & $\begin{array}{l}\text { Strengths: } \\
\text { Weaknesses: }\end{array}$ & & & & & \\
\hline Statistical methods & $\begin{array}{l}\text { Strengths: } \\
\text { Weaknesses: }\end{array}$ & & & & & \\
\hline Approach/interpretation of results & $\begin{array}{l}\text { Strengths: } \\
\text { Weaknesses: }\end{array}$ & & & & & \\
\hline
\end{tabular}

\section{Priority in publishing}

High

Routine

Explain:

Low

To your knowledge, has this material previously been published?

No

Unknown

Yes

\section{Ethical remarks}

Are you are affiliated to the same institution as the author?

Yes

No

Do you have any conflict of interest in reviewing this paper?

No

Explain:

Unknown

Yes

Are you interested in writing an editorial for this paper?

No

Explain:

Yes

Would you be willing to review a revision of this manuscript?

No

Yes

Explain:

Recommendation and comments

Acceptable with no change

Explain:

Acceptable with minor changes

Acceptable with major changes

Reject

Revised manuscript needs further review

\section{Reviewer's suggested references}

Confidential comments to the Editor-in-Chief Explain:

Note: Explain if deemed necessary but not mandatory. 
up the publishing process? Some non-financial incentives could be useful. For instance, by posting annual lists of their reviewers on their journal and/or websites, sending letters of thanks to their most valued and regular reviewers and appointing their best reviewers to their editorial boards. ${ }^{7}$ Reviewing should be considered in the career development and noted on curriculum vitae. Institutions could consider a researcher's involvement in peer review when assessing their performance for promotions. ${ }^{38}$

Table 4. The IMRaD approach: the peer reviewer jobs.

\begin{tabular}{|c|c|c|}
\hline Section & Contents & The peer reviewer has to: \\
\hline Introduction & $\begin{array}{l}\text { The research question is presented in the context of what is } \\
\text { already known about the topic. It identifies the aim of the } \\
\text { research, briefly describing the general methods of } \\
\text { investigation, and outlines the hypothesis and predictions }\end{array}$ & $\begin{array}{l}\text { Determine whether the introduction provides sufficient } \\
\text { background information on the research topic, ensuring that the } \\
\text { research question and hypothesis are clearly identifiable }\end{array}$ \\
\hline Methods & $\begin{array}{l}\text { Describes the experimental procedures and how the research } \\
\text { was conducted, including any tool used in the study and } \\
\text { statistics } \\
\text { The methods section should be detailed enough } \\
\text { to be used in a repeated experiment }\end{array}$ & $\begin{array}{l}\text { Assess the appropriateness of the instruments used to answer the } \\
\text { research question, and if they were presented with sufficient } \\
\text { detail. If something should be missing, the peer reviewer has to } \\
\text { identify details that need to be added }\end{array}$ \\
\hline Results & $\begin{array}{l}\text { The results have to be expressed as: } \\
\text { - Summary of overall results } \\
\text { - Detailed result for one of the experiment's samples } \\
\text { - Detailed result for the other of the experiment's samples } \\
\text { - Further results (comparison between two methods } \\
\text { of sintering) } \\
\text { - Significance of the results } \\
\text { This section can include statistical tests results performed } \\
\text { on data, as well as figures and tables in addition to the text }\end{array}$ & $\begin{array}{l}\text { Ensure that the results are described with sufficient detail and } \\
\text { credibility } \\
\text { Check if excessive numerical data and redundant statistical } \\
\text { results are reported } \\
\text { Control the congruence between text, tables and figures and their } \\
\text { completeness, accuracy, importance, relevance and originality } \\
\text { Check if the figures and tables modified by other authors are } \\
\text { provided with formal permission, according to the editorial } \\
\text { standards }\end{array}$ \\
\hline Discussion & $\begin{array}{l}\text { The results are interpreted and related to past studies } \\
\text { The discussion describes the meaning of the results in terms } \\
\text { of the research question and hypothesis, stating whether the } \\
\text { hypothesis was supported or rejected. In this section you } \\
\text { may provide some possible explanations for unusual results } \\
\text { The discussion should end with a conclusions section that } \\
\text { summarizes the major findings of the investigation, suggesting } \\
\text { the need for future research }\end{array}$ & $\begin{array}{l}\text { Determine whether the discussion is clear and focused, and } \\
\text { whether the conclusions are congruent with the results } \\
\text { presented } \\
\text { Highlight the limitations of the study, any anomalies in the } \\
\text { results, the relationship of the research to previous studies, and } \\
\text { the theoretical implications and practical } \\
\text { applications/limitations of the study }\end{array}$ \\
\hline
\end{tabular}

Source: ${ }^{36,37}$

Table 5. Good and bad reviews.

How to make a good review

Control if the title is descriptive enough, clear and concise

List the major strengths and weaknesses of the paper

Control any grammar, syntax or typographical error of the manuscript and report them to the editor for proofreading

Comment on the logical sequence of paragraphs

Comment on the statistics. Are they appropriate?

Recommend changes to improve the study:

- Suggest changes to improve the data presentation

- Redundancy or inadequacy?

- Tables and figures quality, overlap, duplicating

- Propose clearer formats, if necessary

- Suggest changes to clarify, expand, or reduce sections: introduction,

methods, results, discussion, conclusions, figures, tables, references

Use references to support suggestions

\section{How to make a bad review}

Extreme brevity of the review

Rude, arrogant, with personal judgments and self-referential statements Unclear observations, expressed in an ambiguous manner

Scientific errors (or misquoted literature) or outdated references cited by the reviewer

Sloppy writing with spelling errors and poor grammar

Source: ${ }^{9}$ 


\section{References}

1. Kelly J, Sadeghieh T, Adeli K. Peer review in scientific publications: benefits, critiques, \& a survival guide. EJIFCC 2014;25:227-43.

2. Nardi R, Berti F, Greco A, et al, Complexity in hospital internal medicine departments: what are we talking about? Ital J Med 2013;7:142-55.

3. Jefferson T, Alderson P, Wager E, Davidoff F. Effects of editorial peer review: a systematic review. JAMA 2002;287:2784-6.

4. Maron M, Primack RB, Campos-Arceiz A. Who are the reviewers of journal articles, and how often do they review? Biol Conserv 2017;211:177-82.

5. Ware M. Peer review: benefits, prceptions and alternatives. Publishing Research Consortium (PRC) Summary Papers 2008;4:4-20.

6. Schley D. Peer reviewers satisfied with system. Times Higher Education; September 9, 2009. Available from: http://www.timeshighereducation.co.uk/408108.article

7. Tite L, Schroter S. Why do peer reviewers decline to review? A survey. J Epidemiol Commun Health 2007; 61:9-12.

8. Lerback J, Brooks H. Journals invite too few women to referee. Nature 2017;541:26.

9. Zucker IH. Reviewer guidelines; American Physiological Society. Available from: http://www.theaps.org/mm/Publications/Journals/Reviewer-Guidelines .html

10. University of Groningen. Reviewer guidelines. Available from: http://www.cs.rug.nl/jbi/eurovis2016/ForSubmitters /ReviewerGuidelines

11. Benos DJ, Kevin KL, Hall JE. How to review a paper. Advan Physiol Edu 2003;27:47-52.

12. Turnitin LLC. About Plagiarism.org. Available from: http://www.plagiarism.org

13. Academia. Is verbatim copying several paragraphs of text with citation considered plagiarism? Available from: https://academia.stackexchange.com/questions/20270/is -verbatim-copying-several-paragraphs-of-text-withcitation-considered-plagiarism

14. Watson M. Similarity Check. CrossRef; Last Updated: 2018 May 16. Available from: https://www.crossref.org /services/similarity-check/

15. Errami M, Sun Z, Long TC, et al. Déjà vu: a database of highly similar citations in the scientific literature. Nucleic Acids Res 2009;37:D921-4.

16. iThenticate. Prevent plagiarism in published works. Available from: http://www.ithenticate.com

17. PlagiarismToday. About. Available from: https://www. plagiarismtoday.com/about-plagiarism-today

18. World Association of Medical Editors (WAME). Recommendations on Publication Ethics Policies for Medical Journals. Available from: http://www.wame.org /about/recommendations-on-publication-ethics-policie

19. Italian Journal of Medicine. Peer review process. Available from: http:/www.italjmed.org/index.php/ ijm/about/editorialPolicies\#peerReviewProcess

20. Tomkins A, Zhang M, Heavlin WD. Reviewer bias in single- versus double-blind peer review. Proc Natl Acad Sci U S A 2017;114:12708-13.

21. Chawla DS. Physicists cozy up to double-blind peer review. Physics Today; 26 Oct 2017. Available from: https://physicstoday.scitation.org/do/10.1063/PT.6.1.201 71026a/full/

22. Enago Academy. Single-blind vs. double-blind peer review. Last updated: May 20, 2018. Available from: https://www.enago.com/academy/double-blind-peerreview-for-better-or-for-worse/

23. Conflict of interest in peer-reviewed medical journals. A Policy Statement of the World Association of Medical Editors (WAME). J Child Neurol 2009;24:1321-3.

24. PAGEPress Scientific Publication. PAGEPress style - The reviewer's manual; last updated: September 2016. Available from: http://www.pagepress.org/files/guidelines reviewers.pdf

25. MEDLINE, Google Scholar, PubMed, and OVID. The Cochrane Library is a great resource for health-care interventions. Available from: http://www.cochranelibrary .com

26. CONSORT - Transparent reporting of trials. CONSORT Statement; 2010. Available from: http://www.consortstatement.org/

27. University of Bern. STROBE Statement - What is STROBE? Available from: https://www.strobe-statement. org/index.php?id=strobe-home

28. PRISMA. Transparent reporting of systematic reviews and meta-analyses. Available from: http://www.prismastatement.org/

29. Hoppin FG. How I review an original scientific article. Am J Respir Crit Care Med 2002;166:1019-23.

30. Lucey B. Peer review: how to get it right -10 tips. The Guardian; 27 September 2013. Available from: http://www.theguardian.com/higher-education-network/ blog/2013/sep/27/peer-review-10-tips-research-paper

31. Italian Journal of Medicine. Focus and scope. Available from: http://www.italjmed.org/index.php/ijm/about/ editorialPolicies\#focusAndScope

32. Italian Journal of Medicine. Submission. Available from: http://www.italjmed.org/index.php/ijm/about/submissions

33. Masina M, Gnerre P, Granata P, Nardi R. What to know before starting the process of publishing in a medical journal. Ital J Med 2017;11:325-30.

34. Camps D. The Abstract: The letter of presentation for a scientific paper. Colombia Médica 2010;41:1.

35. OMICS International. Publication policies and ethics. Available from: https:/www.omicsonline.org/ publication -policies-and-ethics.php\#reviewers

36. Huth EJ. Structured abstracts for papers reporting clinical trials. Ann Internal Med 1987;106:626-7.

37. Steingraber S. Guidelines for writing scientific papers, honors organismal biology laboratory manual; 1985. Available from: http://steingraber.com/guidelines-forwriting-scientific-papers/

38. American Physiological Society. Peer Review 101 Advice for Trainees, Junior Faculty, and Mentors; 2013. Available from: http://www.the-aps.org/mm/Science Policy/Agency-Policy/Peer-Review/PeerReview101.pdf 